UDC 615.2

DOI: $10.15587 / 2519-4852.2021 .243526$

\title{
THE EFFECT OF FLUOXETINE AND IMIPRAMINE ON THE IMPROVEMENT OF DEPRESSIVE-LIKE BEHAVIORS AND HPA AXIS (HYPOTHALAMIC- PITUITARY-ADRENAL CORTEX) ACTIVITY - AN ANIMAL MODEL
}

\author{
Raghad Abdulsalam Khaleel, Saja Majeed Shareef, Zinah Essam Hameed, \\ Khulood Majid Alsaraf, Maadh Fawzi Nassar
}

\begin{abstract}
Depression is one of the most common mental disorders and numerous medications are used to reduce the psychotic symptoms.
\end{abstract}

The aim of this study was to evaluate the therapeutic effects of two commonly used antidepressant drugs, including Fluoxetine (Flx) and Imipramine (IMP) to improve depressive-like behaviors as well as the activity of hypothalamic pituitary-adrenal cortex (HPA).

Methods: Initially, 40 adult male albino rats weighing $25 \pm 5 \mathrm{~g}$ were selected for this experimental study. The animals were kept or housed in separate cages under standard temperature $\left(25 \pm 1^{\circ} \mathrm{C}\right)$ and light-dark conditions (12 hours light/dark cycle). Rats were divided into four groups: each group containing 10 rats, control, immobility stress, Flx receiver, and IMP receiver. Polyethylene restrainer was used to induce immobility stress for 14 days. Finally, the parameters of IMT, ST, serum levels of corticosterone and glucose were evaluated in all four mentioned groups.

Results: The results showed that the patient group's immobility time (IMT) increased compared to the control group, but the patient group's swimming time (ST) decreased compared to the control group. The effect of immobility stress on IMT, ST, corticosterone, and glucose factors in the patient group was increasing, increasing, decreasing, and decreasing, respectively, whereas the effect of Flx drug on these mentioned factors was decreasing, increasing, increasing, and increasing, respectively, while the effect of IMP on all mentioned factors was decreasing, increasing, decreasing, and increasing, respectively.

Conclusion: Based on the results, it can be concluded that the antidepressant Flx and IMP drugs have various effects on the HPA activity, and the application of immobility stress causes depressive-behavior. Moreover, Flx is more effective than IMP in the treatment of depressive behaviors

Keywords: Depressive-like behaviors, HPA axis, Fluoxetine, Imipramine, Animal model

\section{How to cite:}

Khaleel, R. A., Khaleel, R. A., Shareef, S. M., Hameed, Z. E., Alsaraf, K. M., Nassar, M. F. (2021). The effect of Fluoxetine and Imipramine on the improvement of depressive-like behaviors and hpa axis (hypothalamic-pituitary-adrenal cortex) activity - an animal model. ScienceRise: Pharmaceutical Science, 5 (33), 79-88. doi: http://doi.org/10.15587/2519-4852.2021.243526

(C) The Author(s) 2021

This is an open access article under the Creative Commons CC BY license hydrate

\section{Introduction}

Depression is a mental disorder that leads people to feel depressed and completely disinterested for the majority or all of the time [1]. Certainly, most healthy individual feel sad from time to time or on occasion, which is the body's natural response to life's problems; but, if sadness persists for an extended period of time, it may lead to disappointment, loss of desire or motivation to live, and depression [2]. Furthermore, depression is often related to reduced attention or impaired focus, mental retardation, guilt feelings and eventually followed by thoughts of death [3]. There are many factors that contribute to depression, but the most important are psycho-biological factors (including serotonergic neurotransmission, norepinephrine, dopamine, and genetics); social-psychological factors (like different life events); and internal stressors (such as changes in serum cholesterol levels, triglycerides, blood glucose and coagulation factors) [4]. More than half of patients between the ages of 20 and 50 are participating in the community, and two- thirds of patients have suicidal thoughts, with 10-15\% committing suicide [5].

As per previous studies, stress and adversity in life are the most significant factors to intensify depression in humans. Unexpected stress factors induce changes in behavioral parameters such as physical, sensorial, and mental activity, eating disorders, and sexuality in animals, much as they do in humans [6]. According to published studies, stress stimulates the release of corticosteroids from the adrenal cortex and thus causes depression through dysfunction of the hippocampus. Decreased serotonin or norepinephrine synaptic levels in different parts of the brain, such as the frontal cortex, and also decreased production of brain-derived neurotrophic factor in the hippocampus may also contribute to stressinduced depression [7]. Moreover, a decrease in serotonin or norepinephrine synaptic levels in various areas of the brain, such as the frontal cortex, as well as a decrease in brain-derived neurotrophic factor activity in the hippocampus, may also lead to stress-induced depression 
$[6,7]$. It was confirmed by previous studies that the decrease in serotonin and norepinephrine in the brain causes depression [8-11].

Tricyclic antidepressants (TCAs) and selective serotonin reuptake inhibitors (SSRIs) are two available drug therapies that affect the neurotransmitters as mentioned above $[9,10]$. The drug fluoxetine (Flx) with the scientific name (N-methyl-3-phenyl-3-[4(trifluoromethyl) phenoxy] propan-1-amine, and under the trade or brand name "Prozac" is one of the SSRIs used to treat neurological disorders such as depression and anxiety [9-11]. For the first time in 1986, an American pharmaceutical company (Eli Lilly) produced structurally formulated fluoxetine (Flx), and then introduced for use in the United States a year later to treat depression [12]. Fluoxetine blocks serotonin reuptake in neurons by inhibiting the action of the serotonin transporter (SERT) [13].

The history of imipramine (IMP) use is much older than selective serotonin reuptake inhibitors (SSRIs), and the history of production, evaluation, and use of imipramine dates back to 1955-1950. Imipramine (3-(10,11-dihydro-5H-dibenzo [b, f] azepin-5-yl) -N, Ndimethylpropan-1-amine) is a class of tricyclic antidepressants (TCAs) and it has a beneficial effect on the treatment of depression and its function is to inhibit the re-absorption of serotonin or norepinephrine, as a result of which the amount of these neurotransmitters in the synaptic cleft increases [14].

Flx and IMP have been shown to have antidepressant effects in previous studies. Antidepressants have<smiles>CN(C)CCCN1c2ccccc2CCc2ccccc21</smiles>

Imipramine (Brand name: Tofranil) also been shown in animal models to be effective in reducing immobility in rodents and, as a result, depressive symptoms [5]. Akhondzadeh et al. (2004) reported that the effect of saffron extract with imipramine (as a common antidepressant used to manage mild to moderate depression), and showed that IMP decreases depressive symptoms despite side effects [15].

According to Chen et al. (2007) study, tricyclic antidepressants (TCAs) can induce hyperglycemia and hyperinsulinemia in rats, while SSRIs decreased blood glucose in rats [16]. Researchers have carried out studies on herbal antidepressants to replace chemical antidepressants because of their side effects, and the results have been reported to be acceptable. For example, the results of a study by Hajrasouliha and Khakpour (2020) showed that Melissa officinalis hydro-alcoholic extract is similar to Flx and reduces depression [17]. In a study by Shafei et al. (2018), who showed that Viola odorata decreases depressive symptoms in the same way that both Flx and IMP [18].

Due to the fact that each antidepressant has different effects, mechanisms, and side effects. In addition, long-term antidepressant chemical use can result in more side effects. Therefore, a medication with higher efficacy properties and fewer side effects is necessary [19]. Because of the above reasons, the main purpose of this study was to evaluate study was to evaluate the efficacy of two well-known antidepressants, fluoxetine and imipramine (Fig. 1) in decreasing symptoms associated with depressive behaviors, as well as their impact on the hypothalamic-pituitary-adrenal cortex (HPA) activity in an animal model.

Fig. 1. The molecular structure of fluoxetine and imipramine

\section{Planning (methodology) of the research}

The methodology was designed as following Fig. 2 to attain the aim of the research.

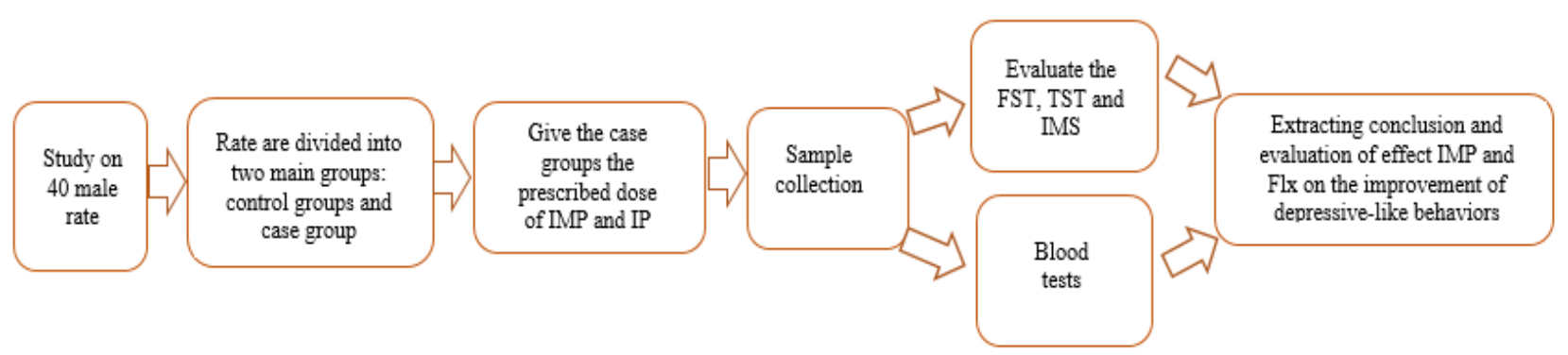

Fig. 2. Algorithm of the research 


\section{Material \& Methods}

Ethical consideration. The present study was submitted to and approved by the animal ethics framework under the supervision of the Institute for the Prevention of Cruelty to Animals and Research Council. Moreover, it was ethically approved by the ethical council of research of the Al-esraa university college, Iraq (456/lq) on 12.10.2020. The European Council Directive (2010/63/EU) recommendations of September 22, 2010, regarding the standards in protecting animals used for experimental purposes, was also followed.

Animals.This study was conducted in the laboratories of the Department of pharmacy, Al- esraa university college in 2021 year. Initially, 40 adult male albino rats weighing $25 \pm 5 \mathrm{~g}$ were selected for this experimental study. The animals were kept or housed in separate cages under standard temperature $\left(25 \pm 1{ }^{\circ} \mathrm{C}\right)$ and light-dark conditions (12 hours light/dark cycle). Throughout this time, the animals were given commercial water and food in sufficient quantities without limits, and each animal was only used once. The ethical standards of working with laboratory animals were observed throughout the experiment, and all experiments were performed throughout the lighting time. A digital balance (accuracy 0.01 ) was used to weigh the animals.

Control and patient groups. In this study, 40 rats were randomly classified into 4 groups: healthy control, patient or disease control, patient groups receiving Flx medication, and disease groups receiving IMP drugs. Group 1: Healthy control group, rats in this group was given only $0.2 \mathrm{~mL}$ distilled water intraperitoneal (IP) for 14 days. Group 2: Patient control group, rats in this group were in fact immobilized stress, rats taken only $0.2 \mathrm{~mL}$ distilled water IP for 14 days Group 3 (patient group taking Flx drugs): Rats under immobilized stress were given $20 \mathrm{mg} / \mathrm{kg}$ body weight Flx drug (dissolved in distilled water) via IP for 14 days. Group 4: the fourth group is similar to the third, but instead of Flx drug, they were given $30 \mathrm{mg} / \mathrm{kg}$ IMP (dissolved in distilled in water) using IP for 14 days (Fig. 3). The amount and method of administering drugs to control and patient rats were based on previous similar studies [17-19].

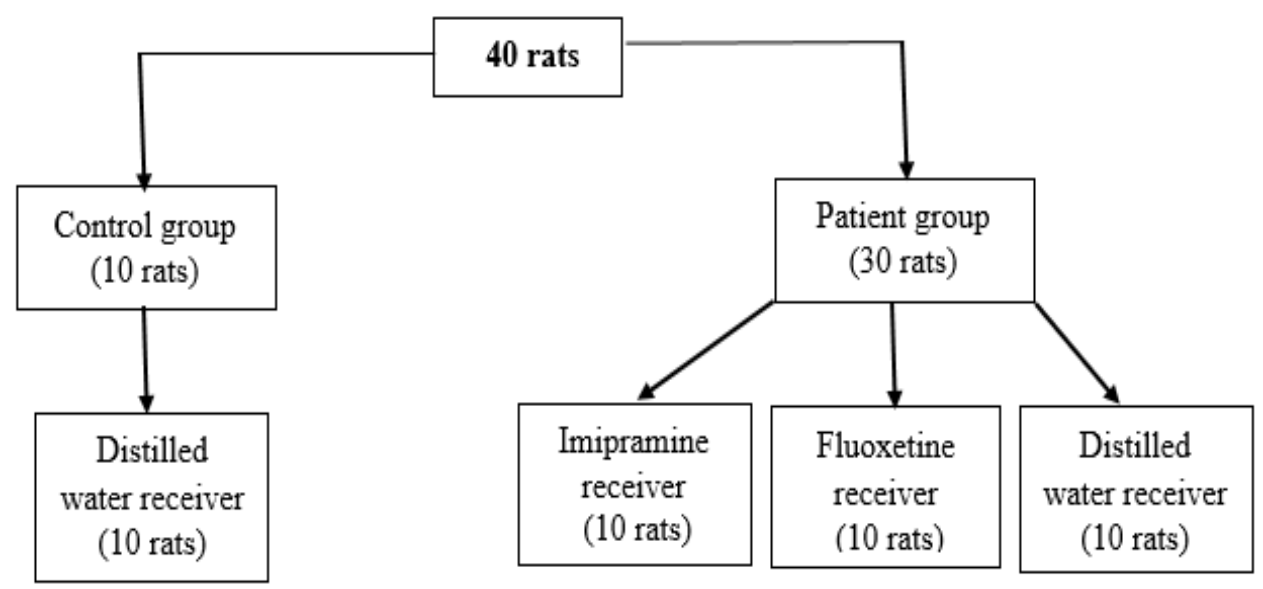

Fig. 3. The procedure of dividing the control and patient groups

Forced swimming test (FST). One of the most common tests to evaluate the antidepressant activity of drug compounds is the forced swimming test (FST) [20, 21]. In this test, immobility time, depressive equivalents and reduction of this time equivalent to antidepressant effect was considered. After injecting Flx, IMP drugs or distilled water separately in a condition with $25 \times 25 \times 25 \mathrm{~cm}$ distance containing water at $25 \pm 1{ }^{\circ} \mathrm{C}$ was considered. Immobility time was usually defined as the lack of limb and foot movements, while swimming time was defined as the rotational movements of the animal around the container. The whole test lasted 6 minutes, the first 2 minutes used to allow the animal to adapt to its environments, and the remaining 4 minutes used to monitor and record each immobility and swimming response in seconds using a stopwatch [18-21].

Tail suspension test (TST). The tail suspension test (TST) is another typical test used to measure the antidepressant effect of drug compounds after the FST. For this purpose, two metal bases with a height of $70 \mathrm{~cm}$ were used and a $50 \mathrm{~cm}$ long string was installed between the two metal bases. The rat tail was tied and protect with a strap. The test then started with a quick and sharp movement of the rat. Thereafter, the rats that were hung from the tail were totally immobile, inactive, and unresponsive, and this time was considered as immobility time. In this test, as in FST, the immobility time, depressive equivalents and reduction of time equivalent to antidepressant effect was recorded by a stopwatch in seconds. The overall test time was 6 minutes; the first 2 minutes were used to allow the animal to adapt to the environment, and the next 4 minutes were used to record the immobility time [17-19].

Immobilization Stress (IST). A polyethylene restrainer was used to apply immobility stress, allowing the rats to lose their mobility as much as possible. Pores were also made in the body of the restrainer for air conditioning. For 14 days, rats were housed or kept at a specific time of day (8-10 am) to avoid other stress factors such as noise, light changes, and temperature changes as much as possible. The rats were returning to their cages in groups of ten after being stressed [19, 22].

Corticosterone and glucose measurement. After TST was completed, all animals were weighed using a scale and then anaesthetized with ether. After anesthesia, the chest was dissected from the xiphoid region of the 
sternum by incision of the diaphragm. Then, a blood sample was collected directly from the animal's heart using a $5 \mathrm{ml}$ syringe, and the samples were centrifuged (for 15 minutes at $3000 \mathrm{rpm}$ ). The serum was separated and stored at $-20{ }^{\circ} \mathrm{C}$ until corticosterone and glucose levels were determined.

Corticosterone was measured using an ELISA kit (according to the kit instructions). Also, according to previous studies, the glucose (GOD-PAP) method was used to measure serum glucose [23]. In this method, the glucose oxidase enzyme causes oxidation of glucose and production of $\mathrm{H}_{2} \mathrm{O}_{2}$ in the presence of peroxidase, paraaminophenazone, and phenol, resulting in a pink complex color and absorption at $500 \mathrm{~nm}$.

The amount of glucose in the sample determines the amount of color-complex formation and, as a result, the amount of absorption. In fact, the glucose-measuring kit includes two reagents: the first reagent contains all the components of the above two reactions and the second reagent is a standard glucose solution with a concentration of $100 \mathrm{ml} / \mathrm{dL}$, with a glucose concentration of up to $400 \mathrm{mg} / \mathrm{dL}$ in this form. Follows Beer-Lambert's law (absorption measured by a spectrophotometer is directly related to concentration $[19,23]$.

Statistical analysis. The various parameters like immobility time (IMT), swimming time (ST), serum corticosterone, and serum glucose levels in healthy control groups were compared to other different group patients (recipients of Flx, IMP, and distilled water) using a oneway ANOVA test at a significant level $(\alpha=0.05)$.

\section{Results}

The results showed that the application of immobility stress to the patient group significantly increased the immobility time compared to the control group
(144.2 compared to 91.9 seconds) $(\mathrm{p}<0.05)$. Moreover, the results showed that administration of Flx to the patient group significantly reduced the immobility time from 144.2 to 70.7 seconds $(\mathrm{p}<0.05)$, while administration of IMP reduced the mentioned time, it was from 144.2 to 128.6 seconds, which was not statistically significant (P>0.001) (Fig. 3, 4, Tables 1, 2).

The results of the present study showed that the mean ST in the control group, the patient group receiving Flx and the patient group receiving IMP were 28.6 \pm 3.1 , $172.7 \pm 12.2$ and $38.8 \pm 5.9$, respectively (Fig. 3, 5). The results of this section of the study revealed that the ST differences between the control and the IMP groups were not significant $(p>0.05)$, but they were significant $(p<0.001)$ between the control and the Flx group $(\mathrm{p}<0.001)$ (Table 1).

Immobilization stress and administration of Flx and IMP caused a significant decrease $(p<0.05)$ in serum corticosterone levels compared to the control group. Based on the results, administration of Flx to animals under immobility stress caused a significant increase in serum corticosterone levels compared to the stressed group who did not receive this drug $(\mathrm{p}<0.001)$.

As opposed to the effect of Flx, there was no significant difference in serum corticosterone levels in the stressed groups with and without IMP (P>0.001) (Fig. 3, 6, Table 1)

The finding of this research revealed that immobility stress significantly reduced the patient group's serum glucose level $(34.2 \mathrm{~g} / \mathrm{dl})$ as comparison to the control group's $(88.4 \mathrm{~g} / \mathrm{dl})$ ( $\mathrm{p}>0.001)$. However, when Flx and IMP were given to immobilize stressed rats, there was no significant difference in serum glucose levels between the control and stressed rats $(\mathrm{p}>0.001)$ (Fig. 3, 7, Table 1).

Table 1

The IMST, ST, corticosterone and glucose in various studied groups

\begin{tabular}{|c|c|c|c|c|c|}
\hline \multirow[b]{2}{*}{ Factors } & \multirow[b]{2}{*}{$\begin{array}{l}\text { Statistical pa- } \\
\text { rameters }\end{array}$} & \multicolumn{4}{|c|}{ Comparison of studied groups } \\
\hline & & $\begin{array}{c}\text { CWOD } \\
n=10\end{array}$ & $\begin{array}{c}\text { PWOD } \\
n=10\end{array}$ & $\begin{array}{c}\text { PWFD } \\
n=10\end{array}$ & $\begin{array}{c}\text { PWID } \\
n=10\end{array}$ \\
\hline \multirow{3}{*}{$\operatorname{IMT}(\mathrm{S})$} & Mean \pm SD & $91.9 \pm 8.1 *$ & $144.0 \pm 9.8 * *$ & $70.7 \pm 6.2 * * *$ & $128.6 \pm 6.7 * * * *$ \\
\hline & Min & 80.2 & 127.3 & 62.8 & 115.9 \\
\hline & Max & 103.4 & 156.3 & 82.4 & 135.7 \\
\hline \multirow{3}{*}{ ST (S) } & Mean \pm SD & $28.6 \pm 3.1 *$ & $36.7 \pm 4.7$ & $172.7 \pm 12.2 * * *$ & $38.9 \pm 5.9$ \\
\hline & Min & 25.1 & 31.9 & 160.4 & 29.7 \\
\hline & Max & 34.5 & 44.7 & 192.9 & 44.1 \\
\hline \multirow{3}{*}{$\begin{array}{l}\text { Corticosterone } \\
(\mu \mathrm{g} / \mathrm{dl})\end{array}$} & Mean \pm SD & $4.73 \pm 0.37 *$ & $0.61 \pm 0.05$ & $2.22 \pm 0.13 * * *$ & $0.51 \pm 0.06^{* * * *}$ \\
\hline & Min & 4.1 & 0.51 & 2.05 & 0.44 \\
\hline & Max & 5.2 & 0.67 & 2.45 & 0.62 \\
\hline \multirow{3}{*}{ Glucose $(\mu \mathrm{g} / \mathrm{dl})$} & Mean \pm SD & $88.4 \pm 3.7 *$ & $34.2 \pm 2.3$ & $55.6 \pm 5.7 * * *$ & $64.1 \pm 2.9 * * * *$ \\
\hline & Min & 82.3 & 30.4 & 48.4 & 59.9 \\
\hline & Max & 93.5 & 38.3 & 63.7 & 68.9 \\
\hline
\end{tabular}

Note: $*-p<0.05$ compared to the CWOD group with other groups, ** $-P<0.05$ compared to the PWOD group with other groups; *** $-p<0.05$ compared to the PWFD group with other groups; **** $-p<0.05$ compared to the PWID group with other groups; $S D$ - Standard deviation; Min - Minimum; Max-Maximum; CWOD - Control group without drugs; PWOD - Patient group without drugs; PWFD - Patient group with Flx drug; PWID - Patient group with IMP drug 


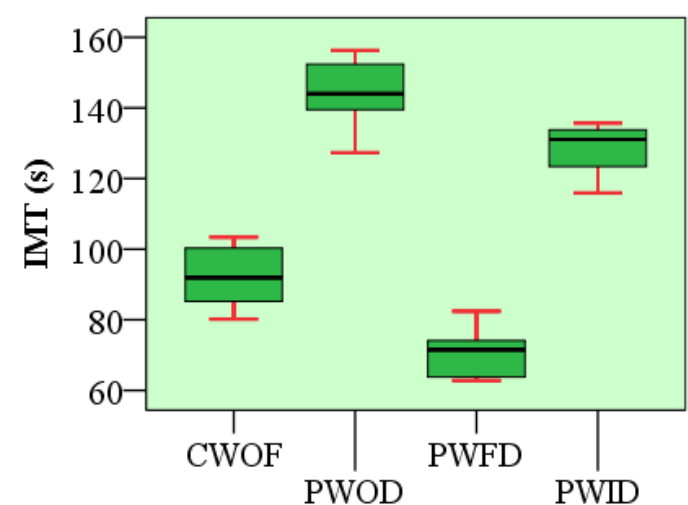

Studied groups

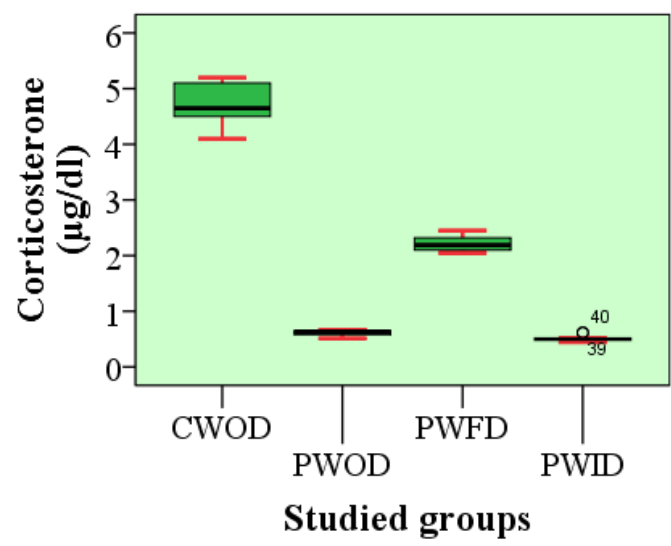

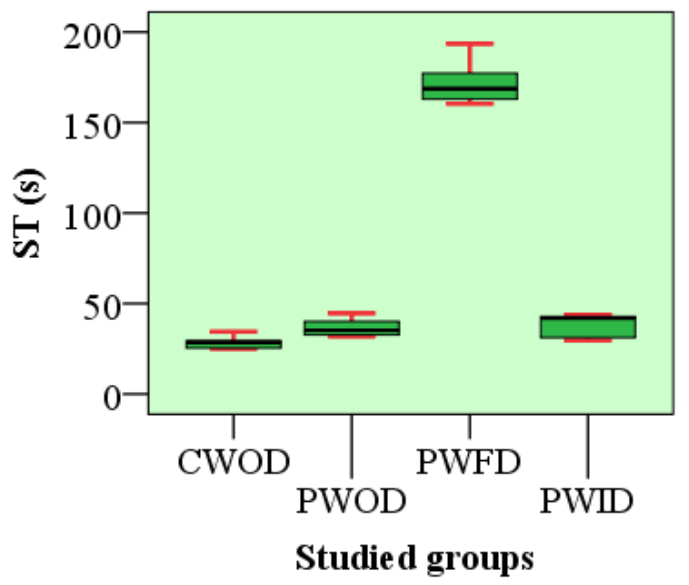

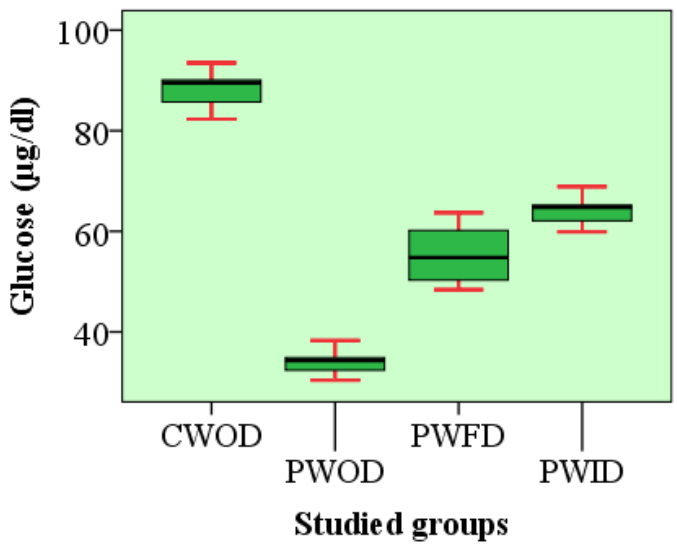

Fig. 3. The box plot related to various variable evaluated between studied groups

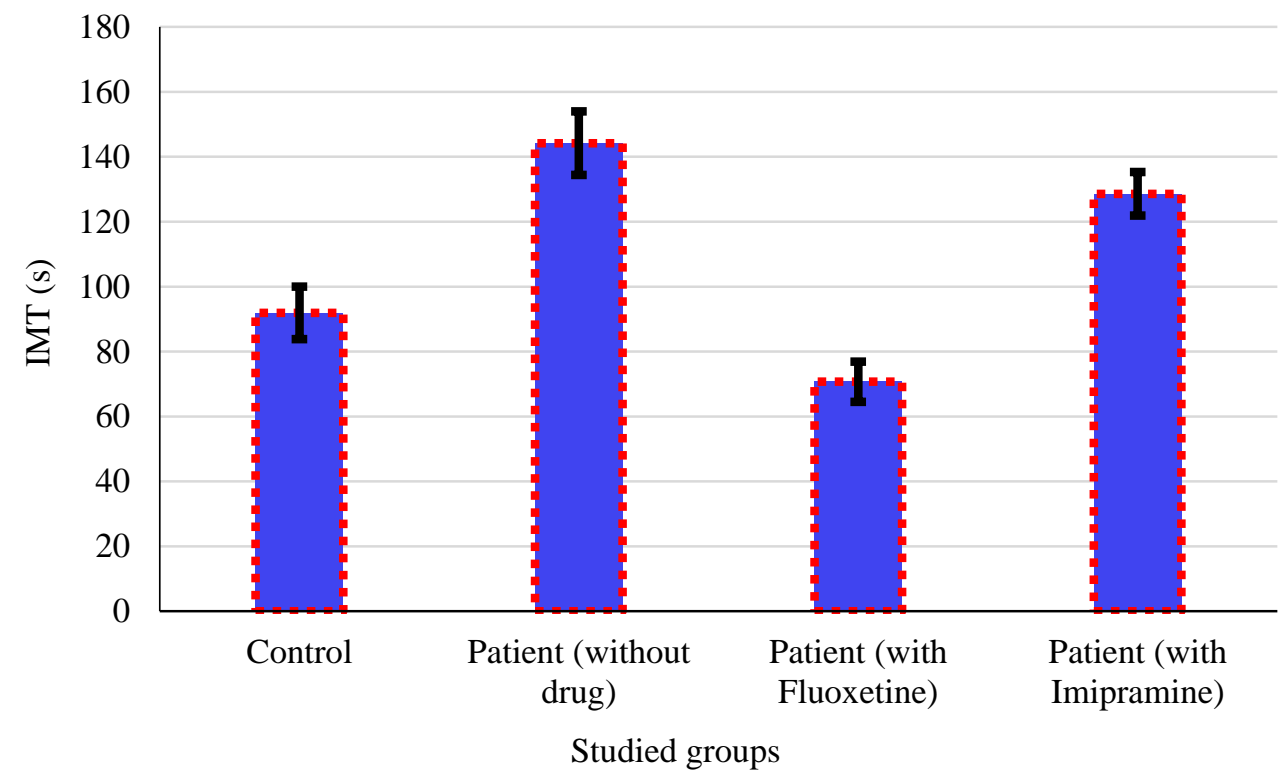

Fig. 4. Comparison of the immobilization stress time between studied groups 


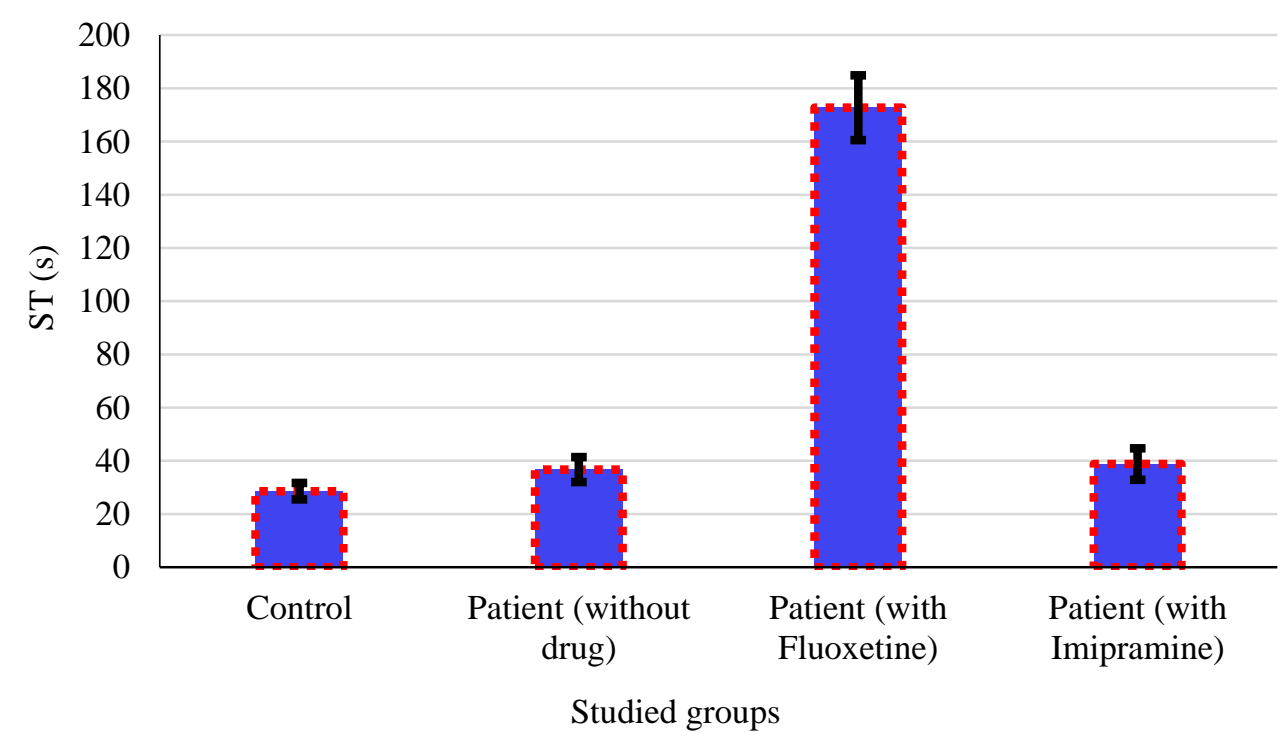

Fig. 5. Comparison of the swimming time between studied groups

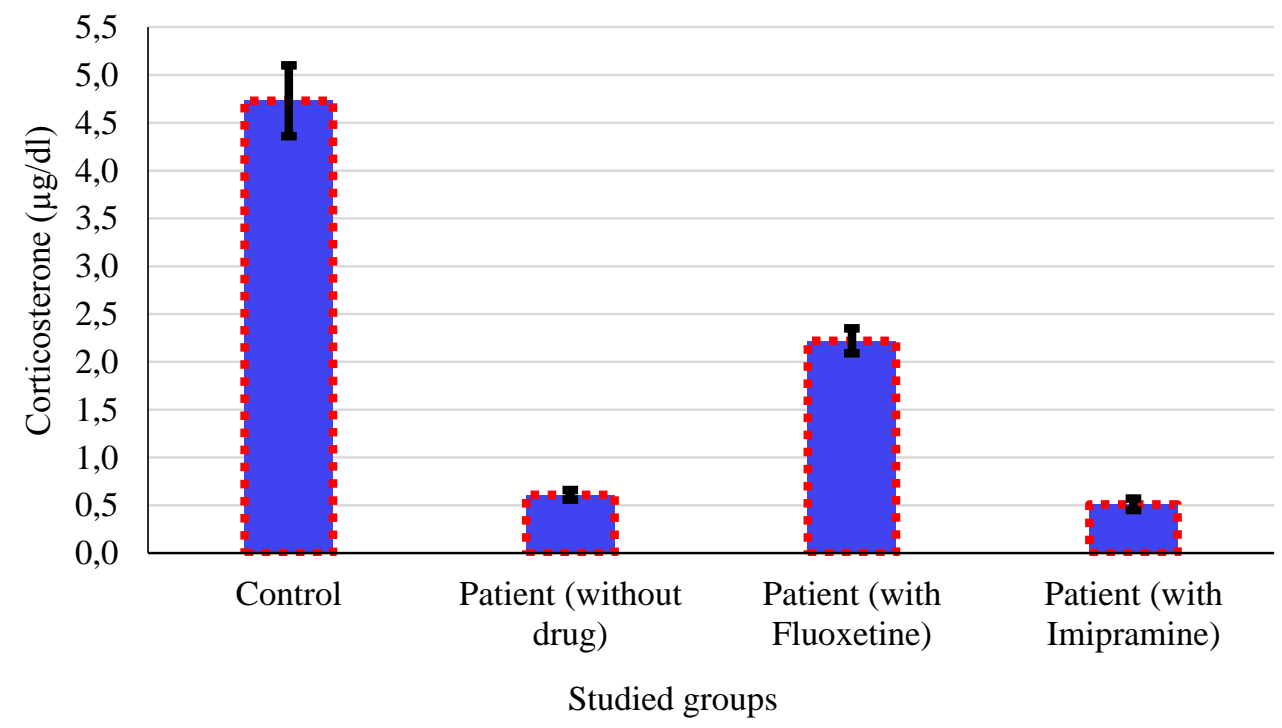

Fig. 6. Comparison of the corticosterone amount between studied groups

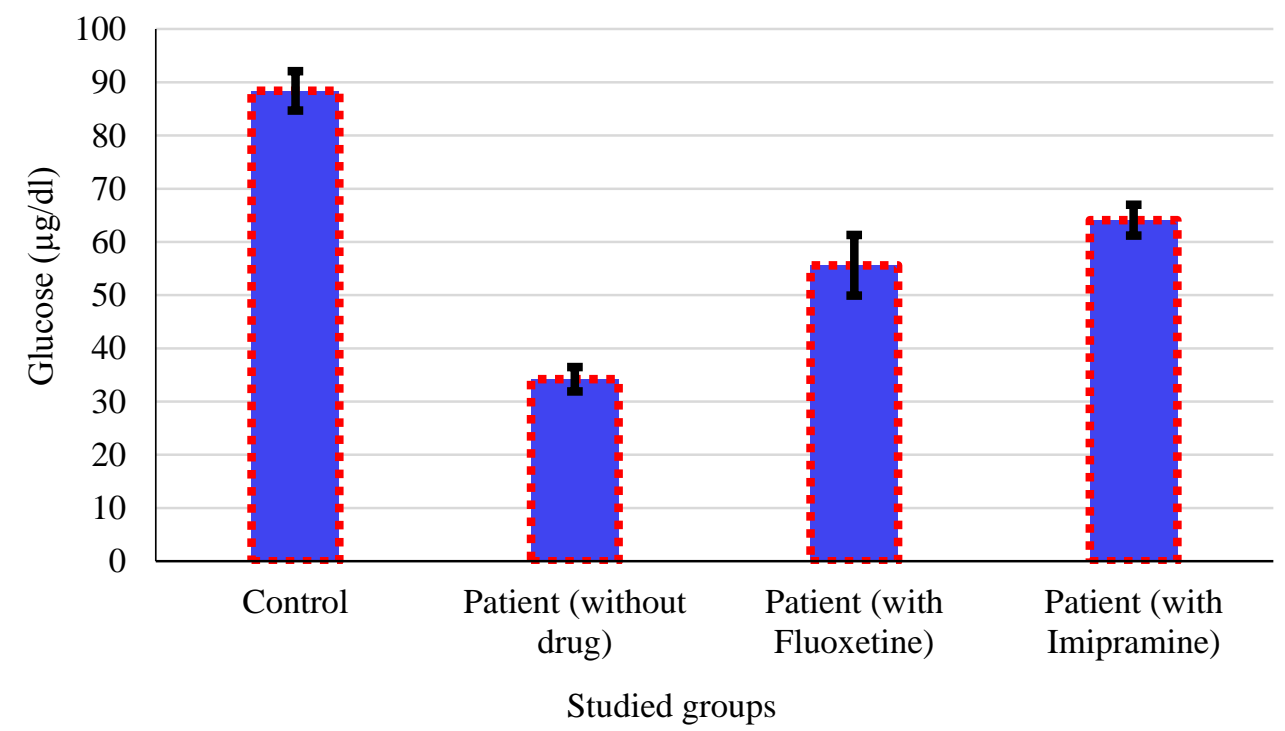

Fig. 7. Comparison of the glucose between studied groups 


\section{Discussion}

The main purpose of this study was to evaluate the effect of Flx and IMP drugs on factors such as immobility time (IMT), swimming time (ST) as well as serum corticosterone and glucose levels (FST) and the tail suspension test (TST), both of which are time-based viewing in an inescapable position, are two common tests for antidepressant activity compounds, after initial attempts to escape, the rats quickly accept immobility. Researchers believe that this change in behavior (immobility) reflects the behavior of depression [24].

The results of the current research revealed that immobility stress causes depressive-like behavior in the patient group. However, Flx and IMP injection reduced depressive-like behavior, with Flx being significantly more effective than IMP. The findings of this research were in accordance with those of several related studies but not with others. In Bayramlou et al. (2018) study, who was reported that in the immobility stress model (for 14 days), administration of Flx or IMP reduces immobility time [19]. Also, Liu et al. (2016) used a model of chronic immobility stress (21 days) to prove that the immobility time in forced swimming test increases in stressed animals [25]. In some recent studies, depressivelike behavior due to persistent or chronic immobility stress has been reported in rodents [26] which is similar with the findings of TST and FST in the present study. However, some studies have not confirmed such behavioral changes after chronic immobility stress [27]. The reasons for this difference can be linked to the characteristics of immobile stress (such as repetition and stress time) [28]. Since serotonin is the biogenic neurotransmitter most associated with depression, a reduction in synaptic serotonin in the patient group may be one of the causes for depressive-like behavior, as long-term stress has been shown to decrease serotonin release in some brain structures [29]. Therefore, it can be assumed that with a high probability, a decrease in serotonin in the brain causes depression and in more severe cases, Alzheimer's disease [8]. Sirisha et al. (2014) found that chronic (7-day) IP injection of Flx at standard doses of 10 and $20 \mathrm{mg} / \mathrm{L}$ in rats decreased immobility time in TST [30]. Nagasawa et al. (2014) reported that oral administration of IMP $(10 \mathrm{mg} / \mathrm{kg}$ ) for 28 days reduced the immobility time in depressed rats [31]. Therefore, since Flx and IMP are among the drugs that influence the serotonergic system and prevent the reabsorption of serotonin at presynaptic ends, this effect may clarify their antidepressant effects. That it increases the inhibition of serotonin reuptake in nerve synapses and reduces depressive symptom [19].

The findings regarding changes in serum corticosterone and glucose levels showed that the application of immobility stress for 14 days caused a significant decrease in these indicators compared to the control group. In this regard, reports indicate that stressful stimuli increase the secretion of corticotrophin-releasing hormone $(\mathrm{CRH})$ from the Para-ventricular nerve nucleus of the hypothalamus, and this neurohormone has a stimulatory effect on the anterior pituitary gland, secretion of adrenocorticotropic hormone (ACTH), and this hormone also increases the secretion of corticosterone from the cortical part of the adrenal glands in rats [32]. However, some studies have shown that when animals are repeat- edly exposed to stress factors, some of the behavioral and physiological effects of the exposure are decreased, and the animals become to get the habit to the stress factors; for example, corticosterone or ACTH levels decrease after repetitive exposure to stress [33]. As a result, one of the causes for the reduction in corticosterone in the current study was the persistence of immobility stress and hence the animal's habituation to the stress factors. On the other hand, reports suggest that glucocorticoids produced by the Hypothalamic-pituitary-adrenal axis (HPA) as a result of stress usually increase gluconeogenesis activity and lead to elevated blood glucose levels [34]. Therefore, according to these findings, the decrease in blood glucose levels in stressed or depressed animals compared to the control group can be explained and related to the decrease in serum corticosterone levels. Since Flx administration increased corticosterone levels compared to the patient group in the current study, but IMP administration has little effect on serum corticosterone levels compared to the patient group. Since studies have shown that Flx and other Flx drugs, as well as other SSRIs, increase hypothalamic secretion and stimulate the HPA axis, Flx tends to increase corticosterone levels by increasing HPA axis activity [35], which in turn causes the secretion of catecholamine. Frost et al. (2003) found that chronic IMP treatment of depressed individuals could modulate HPA axis activity, meaning that the HPA axis could be an effective target for antidepressant efficacy [36]. Other research has shown that IMP increases the expression of glucocorticoid (GR) receptor genes in areas of the brain connected to negative HPA-axis feedback in the early stages [37] and all of these findings support the fact that this group's corticosterone levels are lower than the control groups. Antidepressant treatment for depressive and diabetic patients with mental disorders has since been shown to be one of the most effective ways to increase blood glucose control and improve mood [38].

Most antidepressants increase serotonin and norepinephrine monoaminergic levels, thereby controlling or regulating the activity of HPA, which is associated with major depression and insulin resistance syndrome [39]. Research has also shown that cerebral serotonin is involved in regulating plasma glucose levels, and that electric shock to raphe nuclei leads to a hyperglycemic response, while destruction of serotonergic fibers by specific neurotoxic agents disrupts hyperglycemia due to electric shock in raphe nuclei [40].

Antidepressants, on the other hand, are believed to cause hyperglycemia either by inhibiting the insulin signalling cascade, which leads to insulin resistance, or by interfering with the HPA axis, which leads to insulin resistance. Antidepressants, in fact, can induce hyperglycemia by raising cortisol levels, which causes insulin resistance. Antidepressants, on the other hand, can induce hypoglycemia by increasing insulin sensitivity [41].

Therefore, in the present study, it seems that the increase in serum glucose as a result of Flx or IMP compared to the patient group was related to the increase in synaptic serotonin or inhibition of insulin signalling cascade. It is also thought that Flx (due to its additive effect on serum corticosterone levels compared to the patient group in the present study) caused insulin re- 
sistance by increasing corticosterone levels and thus increased glucose levels compared to the patient group.

Although the antidepressant effects of Flx and IMP were compared in the current study, and the degree of depressive-like behaviors after long-term administration of these drugs in a depressed model due to immobility stress was evaluated, further research is required in this area. Concurrently, the impact of these medications on the hypothalamic-pituitary-adrenal cortex axis (HPA) and, as a result, glucose levels in depressive models should be studied.

Study limitations. Due to financial constraints, it was not possible to test more laboratory animals. In addition, only twice analysis of the desired compounds were performed in the blood of different groups.

Prospects for further research. To achieve better results for use to protect human health, the results of this animal study and other similar studies must be translated into human-applicable results. To do this, uncertainty factors (safety factors) must be used. These factors are used because of the differences in the metabolism of the human and animal bodies and the extrapolation of animal-to-human data.

\section{Conclusion}

The results showed that the patient group's immobility time was significantly increased than the control groups (144.2 compared to 91.9 seconds). However, in comparison to the patient group, immobility time was decreased by fluoxetine (144.2 to 70.7 seconds) and imipramine administration (144.2 to 128.6 seconds). Immobilization stress decreased serum corticosterone and glucose levels significantly compared to control group $(\mathrm{P}>0.001)$, fluoxetine administration increased corticosterone levels compared to the patient group, but imipramine administration had no change. In comparison to the patient group, fluoxetine or imipramine administration increased glucose levels. Based on the current results, it can be concluded that different antidepressants have different effects on improving depressive behaviors and hypothalamic-pituitary-adrenal cortex axis (HPA) activity, which may be due to factors such as different mechanisms of these drugs, as well as dosage and therapeutic time. Finally, it can be concluded that fluoxetine is more effective than imipramine at reducing depressive-like behavior.

\section{Conflict of Interest} interests.

The authors declare that they have no competing

\section{Financing}

This work was financially supported by the selfexpense of the authors.

\section{Acknowledgments}

We would like to acknowledgment the university of Baghdad, college of pharmacy, department of pharmacology and toxicology for providing the facilities to conduct the experimental part.

\section{References}

1. Doron, R., Lotan, D., Einat, N., Yaffe, R., Winer, A., Marom, I. et. al. (2014). A novel herbal treatment reduces depressive-like behaviors and increases BDNF levels in the brain of stressed mice. Life Sciences, 94 (2), 151-157. doi: http://doi.org/10.1016/j.lfs.2013.10.025

2. Cao, X., Li, L.-P., Wang, Q., Wu, Q., Hu, H.-H., Zhang, M. et. al. (2013). Astrocyte-derived ATP modulates depressivelike behaviors. Nature Medicine, 19 (6), 773-777. doi: http://doi.org/10.1038/nm.3162

3. Abildgaard, A., Elfving, B., Hokland, M., Wegener, G., Lund, S. (2017). Probiotic treatment reduces depressive-like behaviour in rats independently of diet. Psychoneuroendocrinology, 79, 40-48. doi: http://doi.org/10.1016/j.psyneuen.2017.02.014

4. Norden, D. M., Devine, R., Bicer, S., Jing, R., Reiser, P. J., Wold, L. E. et. al. (2015). Fluoxetine prevents the development of depressive-like behavior in a mouse model of cancer related fatigue. Physiology \& Behavior, 140, 230-235. doi: http://doi.org/10.1016/ j.physbeh.2014.12.045

5. Park, S.-W., Kim, Y.-K., Lee, J.-G., Kim, S.-H., Kim, J.-M., Yoon, J.-S. et. al. (2007). Antidepressant-like effects of the traditional Chinese medicine kami-shoyo-san in rats. Psychiatry and Clinical Neurosciences, 61 (4), 401-406. doi: http://doi.org/10.1111/j.14401819.2007.01676.x

6. Gałecki, P., Szemraj, J., Bieńkiewicz, M., Zboralski, K., Gałecka, E. (2009). Oxidative stress parameters after combined fluoxetine and acetylsalicylic acid therapy in depressive patients. Human Psychopharmacology: Clinical and Experimental, 24 (4), 277-286. doi: http://doi.org/10.1002/hup.1014

7. Sakr, H. F., Abbas, A. M., Elsamanoudy, A. Z., Ghoneim, F. M. (2015). Effect of fluoxetine and resveratrol on testicular functions and oxidative stress in a rat model of chronic mild stress-induced depression. Journal of Physiology and Pharmacology, 66 (4), 515-527.

8. Salmon, E. (2007). A review of the literature on neuroimaging of serotoninergic function in Alzheimer's disease and related disorders. Journal of Neural Transmission, 114 (9), 1179-1185. doi: http://doi.org/10.1007/s00702-007-0636-5

9. Shah, S. K., Dangre, S. C., Charbe, N. B. (2012). Development of RP-HPLC Method for Simultaneous Estimation of Alprazolam and Fluoxetine Hydrochloride in Pharmaceutical Tablet Dosage Form. Research Journal of Pharmacy and Technology, 5 (7), $938-941$.

10. Cowen, P. (2008). Serotonin and depression: pathophysiological mechanism or marketing myth? Trends in Pharmacological Sciences, 29 (9), 433-436. doi: http://doi.org/10.1016/j.tips.2008.05.004

11. Hellweg, R., Zueger, M., Fink, K., Hörtnagl, H., Gass, P. (2007). Olfactory bulbectomy in mice leads to increased BDNF levels and decreased serotonin turnover in depression-related brain areas. Neurobiology of Disease, 25 (1), 1-7. doi: http://doi.org/10.1016/ j.nbd.2006.07.017

12. Benfield, P., Heel, R. C., Lewis, S. P. (1986). Fluoxetine. Drugs, 32 (6), 481-508. doi: http://doi.org/10.2165/00003495198632060-00002

13. Dixit, N., Trivedi, A., Ahirwar, D. (2020). Synthesis of Citosan Nanocarrier Systems for Improving SSRI-Fluoxetine Efficacy in MDD. Research Journal of Pharmacy and Technology, 13 (5), 2387. doi: http://doi.org/10.5958/0974-360x.2020.00429.1 
14. Zarrindast, M. ., Shamsi, T., Azarmina, P., Rostami, P., Shafaghi, B. (2004). GABAergic system and imipramine-induced impairment of memory retention in rats. European Neuropsychopharmacology, 14 (1), 59-64. doi: http://doi.org/10.1016/s0924$977 x(03) 00068-3$

15. Akhondzadeh, S., Fallah-Pour, H., Afkham, K., Jamshidi, A.-H., Khalighi-Cigaroudi, F. (2004). Comparison of Crocus sativus L. and imipramine in the treatment of mild to moderate depression: A pilot double-blind randomized trial [ISRCTN45683816]. BMC Complementary and Alternative Medicine, 4 (1). doi: http://doi.org/10.1186/1472-6882-4-12

16. Chen, Y.-C., Shen, Y.-C., Hung, Y.-J., Chao-Ha, C., Yeh, C.-B., Perng, C.-H. (2007). Comparisons of glucose-insulin homeostasis following maprotiline and fluoxetine treatment in depressed males. Journal of Affective Disorders, 103 (1-3), $257-261$. doi: http://doi.org/10.1016/j.jad.2007.01.023

17. Hajrasouliha, S., Khakpour, S. (2020). Comparison of antidepressant effect of Melissa officinalis L. hydroalcoholic extract with fluoxetine in male mice. Medical Science Journal of Islamic Azad Univesity-Tehran Medical Branch, 30 (4), 418-424. doi: http://doi.org/10.29252/iau.30.4.418

18. Shafei, Z., Abbasi Maleki, S., Ghaderi-Pakdel, F. (2018). Evaluation of the antidepressant-like effect of Viola odorata hydroalcoholic extract in male mice. Journal of Birjand University of Medical Sciences, 25 (4), 286-296.

19. Bayramlou, R., Mohammadzadeh, M., Babaei Balderlou, F. (2018). A Comparative Survey of the Effects of Fluoxetine and Imipramine on Depression-Like Behavior and Serum Levels of Corticosterone and Glucose in Male Rats under Immobilization Stress. Qom University of Medical Sciences Journal, 12 (2), 1-10. doi: http://doi.org/10.29252/qums.12.2.1

20. Wang, W., Hu, X., Zhao, Z., Liu, P., Hu, Y., Zhou, J. et. al. (2008). Antidepressant-like effects of liquiritin and isoliquiritin from Glycyrrhiza uralensis in the forced swimming test and tail suspension test in mice. Progress in Neuro-Psychopharmacology and Biological Psychiatry, 32 (5), 1179-1184. doi: http://doi.org/10.1016/j.pnpbp.2007.12.021

21. Dias Elpo Zomkowski, A., Oscar Rosa, A., Lin, J., Santos, A. R. S., Batista Calixto, J., Lúcia Severo Rodrigues, A. (2004). Evidence for serotonin receptor subtypes involvement in agmatine antidepressant like-effect in the mouse forced swimming test. Brain Research, 1023 (2), 253-263. doi: http://doi.org/10.1016/j.brainres.2004.07.041

22. Mitic, M., Simic, I., Djordjevic, J., Radojcic, M. B., Adzic, M. (2013). Gender-specific effects of fluoxetine on hippocampal glucocorticoid receptor phosphorylation and behavior in chronically stressed rats. Neuropharmacology, 70, 100-111. doi: http://doi.org/10.1016/j.neuropharm.2012.12.012

23. Roghani, M., Arbab-Soleymani, S. (2013). The Effect of Oral Feeding of Tribulus Terrestris Fruit on Some Markers of Oxidative Stress in the Brain of Diabetic Rats. SSU_Journals, 21 (2), 127-135.

24. Pytka, K., Podkowa, K., Rapacz, A., Podkowa, A., Żmudzka, E., Olczyk, A. et. al. (2016). The role of serotonergic, adrenergic and dopaminergic receptors in antidepressant-like effect. Pharmacological Reports, 68 (2), 263-274. doi: http://doi.org/10.1016/ j.pharep.2015.08.007

25. Liu, L., Zhou, X., Zhang, Y., Liu, Y., Yang, L., Pu, J. et. al. (2016). The identification of metabolic disturbances in the prefrontal cortex of the chronic restraint stress rat model of depression. Behavioural Brain Research, 305, 148-156. doi: http://doi.org/10.1016/j.bbr.2016.03.005

26. Yoon, S. H., Kim, B.-H., Ye, S.-K., Kim, M.-H. (2014). Chronic Non-Social Stress Affects Depressive Behaviors But Not Anxiety in Mice. The Korean Journal of Physiology \& Pharmacology, 18 (3), 263. doi: http://doi.org/10.4196/kjpp.2014.18.3.263

27. Parihar, V. K., Hattiangady, B., Kuruba, R., Shuai, B., Shetty, A. K. (2009). Predictable chronic mild stress improves mood, hippocampal neurogenesis and memory. Molecular Psychiatry, 16 (2), 171-183. doi: http://doi.org/10.1038/mp.2009.130

28. Buynitsky, T., Mostofsky, D. I. (2009). Restraint stress in biobehavioral research: Recent developments. Neuroscience \& Biobehavioral Reviews, 33 (7), 1089-1098. doi: http://doi.org/10.1016/j.neubiorev.2009.05.004

29. Safari, H., Miladi Gorji, H. (2013). Anxiety-like behavior profile in morphine dependent rats exposed to acute and chronic stress. Tehran University Medical Journal, 709-716.

30. Sirisha, G., Prakash, R. A., Usha, N. S. (2014). Evaluation of antidepressant effect of chronic administration of tramadol alone and in combination with fluoxetine in low doses in albino mice. International Journal of Pharmacy and Pharmaceutical Sciences, 6 (6), 101-105.

31. Nagasawa, M., Otsuka, T., Yasuo, S., Furuse, M. (2015). Chronic imipramine treatment differentially alters the brain and plasma amino acid metabolism in Wistar and Wistar Kyoto rats. European Journal of Pharmacology, 762, 127-135. doi: http://doi.org/10.1016/j.ejphar.2015.05.043

32. Heidari, M. (2014). The effect of interference of morphine and immobility stress on performance of pituitary-adrenal axis in mature male rats. Hormozgan Medical Journal, 18 (1), 11-20.

33. Heidari Oranjaghi, N., Ghasemi, E., Mahdipour, H., Salehi, B., Sofiabadi, M., Erami, E., Azhdari Zarmehri, H. (2012). Effects of acute and chronic immobilization stress on formalin test on the male rat. Journal of Rafsanjan University of Medical Sciences, 11 (4), 391-402.

34. Fagerholm, V., Haaparanta, M., Scheinin, M. (2011). a2-Adrenoceptor Regulation of Blood Glucose Homeostasis. Basic \& Clinical Pharmacology \& Toxicology, 108 (6), 365-370. doi: http://doi.org/10.1111/j.1742-7843.2011.00699.x

35. Hashemi, S. S., Jelodar, G. A., Rafati, A. (2014). Investigating the effects of fluoxetine on cortisol and thyroid hormone levels in rats. Journal of Arak University of Medical Sciences, 17 (2), 82-89.

36. Frost, P., Bornstein, S., Ehrhart-Bornstein, M., O'Kirwan, F., Hutson, C., Heber, D. et. al. (2003). The Prototypic Antidepressant Drug, Imipramine, but not Hypericum perforatum (St. John's Wort), Reduces HPA-Axis Function in the Rat. Hormone and Metabolic Research, 35 (10), 602-606. doi: http://doi.org/10.1055/s-2003-43507

37. Heydendael, W., Jacobson, L. (2010). Widespread hypothalamic-pituitary-adrenocortical axis-relevant and mood-relevant effects of chronic fluoxetine treatment on glucocorticoid receptor gene expression in mice. European Journal of Neuroscience, 31 (5), 892-902. doi: http://doi.org/10.1111/j.1460-9568.2010.07131.x

38. Bambauer, K. Z., Soumerai, S. B., Adams, A. S., Mah, C., Zhang, F., McLaughlin, T. J. (2004). Does Antidepressant Adherence Have an Effect on Glycemic Control among Diabetic Antidepressant Users? The International Journal of Psychiatry in Medicine, 34 (4), 291-304. doi: http://doi.org/10.2190/kkgw-y42p-baab-jdj0 
39. McIntyre, R. S., Soczynska, J. K., Konarski, J. Z., Kennedy, S. H. (2005). The effect of antidepressants on glucose homeostasis and insulin sensitivity: synthesis and mechanisms. Expert Opinion on Drug Safety, 5 (1), 157-168. doi: http://doi.org/10.1517/14740338.5.1.157

40. Carvalho, F., Barros, D., Silva, J., Rezende, E., Soares, M., Fregoneze, J., De Castro e Silva, E. (2004). Hyperglycemia induced by acute central fluoxetine administration: role of the central CRH system and 5-HT3 receptors. Neuropeptides, 38 (2-3), 98-105. doi: http://doi.org/10.1016/j.npep.2004.04.004

41. Khoza, S., Barner, J. C. (2011). Glucose dysregulation associated with antidepressant agents: an analysis of 17 published case reports. International Journal of Clinical Pharmacy, 33 (3), 484-492. doi: http://doi.org/10.1007/s11096-011-9507-0

Received date 27.09.2021

Accepted date 26.10.2021

Published date 29.10.2021

Raghad Abdulsalam Khaleel, Department of Pharmacology, College of Medicine, Al Iraqia University, Baghdad, Iraq, 10071

Saja Majeed Shareef, Department of pharmacy, Al-Esraa University College, Baghdad, Iraq, 10071

Zinah Essam Hameed, Department of pharmacy, Al-Esraa University College, Baghdad, Iraq, 10071

Khulood Majid Alsaraf, Department of pharmacy, Al-Esraa University College, Baghdad, Iraq, 10071

Maadh Fawzi Nassar, Department of Chemistry, Faculty of Science, University Putra Malaysia, UPM Serdang, Selangor, Malaysia, 43400, Email: nassarmaadh@gmail.com,

*Corresponding author: Maadh Fawzi Nassar, e-mail: nassarmaadh@gmail.com 